\title{
The ghost of herbivory past: slow defence relaxation in the chlorophyte Scenedesmus obliquus
}

\author{
Antonie M. VERSCHOOR*, Ozan K. BEKMEZCI ${ }^{1)}$, Ellen VAN DONK and Jacobus VIJVERBERG \\ Netherlands Institute of Ecology (NIOO-KNAW), Centre for Limnology, Department of Aquatic Food Webs, Rijksstraatweg 6, 3631 \\ AC Nieuwersluis, The Netherlands \\ ${ }^{1)}$ Middle East Technical University, Department of Biological Sciences, 06531 Ankara, Turkey \\ *e-mail corresponding author: a.verschoor@nioo.knaw.nl
}

\begin{abstract}
The freshwater chlorophyte Scenedesmus obliquus (Turpin) Kützing produces colonies as an inducible defence against herbivores. We investigated the dynamics of Scenedesmus colony formation and disintegration in response to the density of the herbivorous rotifer Brachionus calyciflorus in large-scale mesocosms. Additional bioassays were performed to investigate Scenedesmus colony disintegration under different light regimes. In the mesocosm experiment, colony formation took place rapidly, but relaxation towards the initial size took relatively long $(>10$ d) after cessation of herbivory. In the bioassays, in the absence of infochemicals, colonies disintegrated almost immediately in the dark (1-1.5 d), within $4 d$ under a photoperiod of 16:8 (L:D) and between 8 and 12 days under full light. Colony disintegration times in the mesocosm experiment were substantially longer as compared to treatments with the same photoperiod (L:D 16:8) in the bioassays. So after a peak of herbivory, the 'ghost of herbivory past', i.e. the remaining infochemicals, may continue to induce colony formation, causing an additional lengthening of colony disintegration times and associated fitness costs (higher sedimentation loss rates). This indicates that costs of colony formation are not only important during the induction phase, but may be even more important during the relaxation phase. We compared these sedimentation costs to the costs of herbivory for differently sized Scenedesmus, and found a clear trade-off pattern for these costs.
\end{abstract}

Key words: colony formation, defence cycle, Desmodesmus quadricauda, inducible defenses, Scenedesmaceae

\section{INTRODUCTION}

Inducible defences have been found across numerous taxa and habitats in nature (Tollrian \& Harvell 1999). The cosmopolitan freshwater chlorophyte genus Scenedesmus has been used extensively in studies on the consequences of inducible defences for the structure and functioning of pelagic ecosystems, both theoretical (e.g., Vos et al. 2004a, 2004b) and empirical (e.g., Verschoor et al. 2004b; Van der Stap et al. 2007). The discovery of zooplankton-induced colony formation in Scenedesmus (Hessen \& Van Donk 1993; Lampert et al. 1994) has stimulated much research on inducible defences within this genus, both on the mechanism of colony formation and on its adaptive significance for Scenedesmus.

The information chemical (infochemical) that induces colony formation in Scenedesmus appears to be released by actively feeding zooplankton (Lampert et al. 1994; Von Elert \& Franck 1999). Different taxa of herbivorous zooplankton species are capable of colony induction in Scenedesmus, and average colony size is proportional to the actual grazing pressure (Lürling 2003a; Verschoor et al. 2004a). Long-lasting attempts to identify the active compounds of the "Daphnia pulex kairomone" have found 4,8-dimethylnonyl sulphate and 3-methyl-4E-decenyl sulphate to induce colony formation in S. gutwinskii var. heterospina Bodrogközy NIES-802 (Yasumoto et al. 2008). Nevertheless it remains unclear whether these compounds have the same effects on other Scenedesmus species such as $S$. obliquus, and whether other Daphnia species, or even other herbivorous zooplankton species release the same or similar colony-inducing compounds (i.e., aliphatic sulphates).

Although large Daphnia release these infochemicals, inducible colony formation did not prove to be an effective defence against these zooplankters (Lampert et al. 1994; Lürling \& Van Donk 1997; Van Donk et al. 1999). It has therefore been suggested that inducible colony formation should be most effective against small herbivores (Van Donk et al. 1999). Colony formation might be an effective defence against grazing by smaller Daphnia species, such as D. cucullata (Lürling \& Van Donk 1997; Van Donk et al. 1999). Quite recently, both colony induction and adaptive benefits of colony formation have been investigated with one and the same (small) herbivore on Scenedesmus obliquus (Turpin) Kützing (Verschoor et al. 2007). The rotifer Brachionus calyciflorus is capable of inducing colonies in $S$. obliquus, and even natural lake water containing $B$. calyciflorus may do so (Lürling \& Van Donk 1997).

Induced Scenedesmus colonies lower the ingestion and assimilation rates of the rotifer, due to their longer handling times (Verschoor et al. 2007). Such inducible defences which affect predator handling times have been predicted to stabilise population dynamics (Vos et al. 2004a) and to affect trophic structure (Vos et al. 
2004b). Experiments with bi- and tritrophic laboratory communities, consisting of undefended or inducibly defended Scenedesmus, B. calyciflorus and the carnivorous rotifer Asplanchna brightwelli, confirmed these theoretical predictions, both for the stabilising effect on population dynamics (Verschoor et al. 2004b), as well as for the dampening effect on the trophic cascade (Van der Stap et al. 2007). This indicates that Scenedesmus colony formation, and more generally inducible defences, have an effect on the structure and functioning of (aquatic) food webs.

Although colony formation has adaptive benefits, it also involves costs. If these costs are high they may prevent colony formation in the field. Colony formation reduces the surface to volume ratio of Scenedesmus, and hence this could lower the organism's light or nutrient uptake rates. Even so, no differences in growth rates (Hessen \& Van Donk 1993, Lampert et al. 1994; Lürling \& Van Donk 2000) or in photosystem II quantum efficiency (Lürling \& Van Donk 2000) have been found between unicells and colonies of Scenedesmus. The only costs that have been demonstrated unambiguously for Scenedesmus colonies are increased sedimentation rates (Lürling \& Van Donk 2000). Yet it should be considered that most research on the costs of colony formation has been performed under constant laboratory conditions. Although colony formation apparently does not affect light harvesting capacity, light is an essential prerequisite for autotrophic growth and, hence, light is an important requirement for formation and maintenance of colonies in the Chlorococcales (e.g., Dehning \& Tilzer 1989; Boraas et al. 1998). Sedimentation of induced colonies may thus cause Scenedesmus to settle to depths with lower light intensity, where it disintegrates and hence loses its defensive properties (Lürling 2003b). In natural systems, the light quality and quantity varies both spatially (e.g., with depth) and temporally: daylight intensity is never constant and every light period (day) is followed by a dark period (night), which puts important constraints on Scenedesmus colony formation in the field.

Another factor which varies dynamically under field conditions is the concentration of infochemicals. Most research on infochemical-induced colony formation in Scenedesmus has been performed using standard bioassays with fixed infochemical concentrations. In natural ecosystems, the population density of herbivores varies dynamically, causing continuously varying concentrations of herbivore-released infochemicals. Furthermore, biodegradation by e.g. bacteria will cause the infochemical signal to weaken over time. The combination of herbivore population dynamics and environmental degradation will thus create highly dynamic infochemical concentrations and gradients, resulting in dynamic patterns of colony formation and disintegration (Lürling \& Van Donk 1997). Such dynamics cannot be inferred from short-term, well-mixed laboratory envi- ronments but require experiments over larger temporal and spatial time scales.

Here, we investigate the dynamics of Scenedesmus colony formation and disintegration in response to the densities of the herbivorous rotifer Brachionus in large laboratory mesocosms, under a light:dark cycle. Early (unexpected) extinction of Brachionus during this experiment allowed us to compare defence levels and fitness of the algae, first in the presence of the herbivore, but also during absence of the herbivore, and thus to assess the importance of these aspects over the full defence cycle. Additional bioassays were performed to investigate the dynamics of colony disintegration under different light regimes.

We address the following questions: 1) What is the effect of the length of the light period on the persistence of Scenedesmus colonies; 2) What is the effect of colony formation on the Scenedesmus loss rates due to sedimentation; 3) How fast will Scenedesmus respond to grazer released infochemicals when defences are induced by high densities of grazers and how much time does it take after the disappearance of the grazers from the water column for Scenedesmus colonies to disintegrate to single cells; and 4) How do lower loss rates due to reduced grazing trade off against loss rates due to higher sedimentation rates? Thus, we sought to gain insight in the defence cycle of Scenedesmus and the trade-offs involved during different phases of this cycle, which helps us in assessing the adaptive significance of inducible colony formation for Scenedesmus obliquus.

\section{METHODS}

\subsection{Experimental systems}

Ideally, our questions should be investigated under field conditions, i.e. where light varies (both with depth and with night and day), where sedimentation and natural dynamics of grazing and infochemical degradation can take place. However, natural systems are notoriously variable, and have many confounding factors which cannot be controlled. Therefore, we used large scale laboratory mesocosms which had a volume of approximately $1 \mathrm{~m}^{3}, 1.35 \mathrm{~m}$ deep and $0.97 \mathrm{~m}$ wide. These Limnotrons (Verschoor et al. 2003) have the desired degree of spatial heterogeneity, are sufficiently large to allow population dynamics of algae (including sedimentation) and herbivores, and yet offer control over various physical and chemical parameters (e.g., light, mixing, temperature, nutrients). This enabled us to investigate colony induction and disintegration of Scenedesmus under controlled semi-natural conditions. The subsequent rise and fall of the herbivorous rotifer Brachionus during this experiment allowed us to compare defence levels and fitness of the algae during the induction and defence phase (in the presence of the herbivore) and during the relaxation phase (in the absence of the herbivore). In addition to the mesocosm experiments, we performed bioassays to investigate the effects 
of three light cycles (constant light, a light-dark cycle and constant darkness) on the colony disintegration process of $S$. obliquus in the absence of herbivore infochemicals.

\subsection{Limnotron experiment}

We ran our experiment for 18 days in six Limnotrons. The abiotic conditions were chosen to resemble conditions during the growth season in shallow hypertrophic lakes, the natural habitat of Scenedesmus and Brachionus (Pourriot 1965; Jeppesen et al. 1990). After initial disinfection, the Limnotrons were filled with tapwater diluted COMBO medium (Kilham et al. 1998) and adjusted to initial total inorganic phosphorus and nitrogen concentrations of 0.7 and $4.5 \mathrm{mg} \mathrm{L}^{-1}$, respectively. Next each Limnotron was inoculated at day 0 with $4.4 \mathrm{~mm}^{3} \mathrm{~L}^{-1}\left(58 \times 10^{6}\right.$ cells $\left.\mathrm{L}^{-1}\right)$ Scenedesmus obliquus (strain originating from the Max Planck Institute of Limnology [MPI], Plön, Germany) that had been precultured in $20 \mathrm{~L}$ batch cultures. The Limnotrons were set at $17.5^{\circ} \mathrm{C}$, constant slow mixing (impeller set at 0.5 rotations per minute) and a $16: 8 \mathrm{~h}$ light-dark cycle, with a surface irradiation of $120 \mu \mathrm{mol}$ quanta (photosynthetically active radiation $[\mathrm{PAR}]$ ) $\mathrm{m}^{-2} \mathrm{~s}^{-1}$. At day 1 , three Limnotrons, the herbivore treatments, were inoculated with 350 Brachionus calyciflorus $\mathrm{L}^{-1}$ (hatched from cysts: Microbiotest Inc., Nazareth, Belgium); the other three Limnotrons served as controls. Three times per week, $\mathrm{pH}$ and dissolved oxygen were measured, and samples were taken for nutrients, phytoplankton and zooplankton. Phytoplankton and zooplankton were separated by a $30 \mu \mathrm{m}$ filter. Volume lost by evaporation and sampling was replaced by fresh medium, corresponding to average inorganic phosphorus and nitrogen loadings of $0.01 \mathrm{mg} \mathrm{L}^{-1} \mathrm{~d}^{-1}$ and $0.07 \mathrm{mg}$ $\mathrm{L}^{-1} \mathrm{~d}^{-1}$, respectively.

Seston particle concentrations (PC), total particle volume ('biovolume') concentrations (PVC) and mean particle volumes $(\mathrm{MPV}=\mathrm{PVC} / \mathrm{PC}$ ) were counted using a Coulter Multisizer II electronic particle counter (Beckman Coulter Inc., Fullerton, CA, USA) with a 100 $\mu \mathrm{m}$ orifice. Microscope samples were fixed in $1 \%$ (vol) Lugol's iodine solution and inspected by light microscope on infections or lysis of the algal cells. Zooplankton samples were fixed in Lugol's solution and counted at $10 \times-40 \times$ magnification under a dissecting microscope. Nutrients measured were: soluble reactive phosphorus (SRP), dissolved organic phosphorus (DOP), particulate phosphorus (POP), ammonium $\left(\mathrm{NH}_{4}\right)$, nitrate $\left(\mathrm{NO}_{3}\right)$, and bicarbonate $\left(\mathrm{HCO}_{3}\right)$. We also performed molecular analyses of the eukaryotic and prokaryotic communities as an additional check on plankton species composition. To do this, seston was harvested onto a $0.2 \mu \mathrm{m}$ nitro-cellulose membrane filter, followed by DNA extraction. After DNA purification, PCR amplifications were performed on both the $16 \mathrm{~S}$ prokaryotic subunit and on the $18 \mathrm{~S}$ eukaryotic subunit of the rRNA gene. To investigate and characterise the prokaryotic and eukaryotic community structures, we used Denaturing Gradient Gel Electrophoresis (DGGE).Verschoor et al. (2003) give further details on analytical and molecular methods applied.

As data were non-normal and heteroscedastic, the Mann-Whitney U-test was used to compare the results of the controls and treatments. In order to compare growth and decline (loss) rates, biovolume concentrations at different days were first $\ln$-transformed, and then linear regressions and slope comparisons were done according to Sokal \& Rohlf (2000, boxes 14.4 and 1.7). The slopes of these regressions thus represent the actual exponential growth or loss rates.

\subsection{Bioassay experiment}

In the Limnotron experiments, we observed that Scenedesmus colonies persisted for several days after the decline of the herbivore. To determine whether this was due to slowly degrading herbivore infochemicals, we did additional bioassays on colony disintegration in the absence of herbivore infochemicals under three different light conditions: full light, a light:dark cycle, and full darkness. First, algae were exposed to herbivore infochemicals or control medium. Herbivore infochemicals were produced by $24 \mathrm{~h}$ incubation of $160 \mathrm{~B}$. calyciflorus $\mathrm{mL}^{-1}$ with $65 \mathrm{~mm}^{3} \mathrm{~S}$. obliquus $\mathrm{L}^{-1}$ in COMBO medium at $20{ }^{\circ} \mathrm{C}$ in the dark, which was then filtered over a pre-combusted glass fibre filter (Whatman GF/F). Control medium was produced similarly, but without $B$. calyciflorus. From a chemostat with $S$. obliquus (dilution rate $1.2 \mathrm{~d}^{-1}$ ), $25 \mathrm{~mm}^{3}$ algae $\mathrm{L}^{-1}$ were inoculated in 1 $\mathrm{L}$ bottles, containing $800 \mathrm{~mL}$ of COMBO medium, and $200 \mathrm{~mL}$ test water. Algae were then incubated for $48 \mathrm{~h}$ at $100 \mathrm{rpm}$, continuous light $\left(120 \mu \mathrm{mol} \mathrm{PAR} \mathrm{m} \mathrm{m}^{-2} \cdot \mathrm{s}^{-1}\right.$, the same as the surface intensity in the Limnotron experiments) and $20^{\circ} \mathrm{C}$. After incubation, the algae were centrifuged for $10 \mathrm{~min}$ at $2500 \mathrm{rpm}$, the pellet was resuspended in $1 \mathrm{~L}$ of fresh COMBO medium, and this suspension was centrifuged and resuspended again, for both infochemical treatments and controls. In this way the infochemicals were removed from the infochemical treatment so that induced colonies and control algae had comparable chemical conditions. $250 \mathrm{~mL}$ cellulose-plug stoppered Erlenmeyer bottles were inoculated with 10 $\mathrm{mm}^{3} \cdot \mathrm{L}^{-1}$ of either type of algae, in a total volume of 100 $\mathrm{mL}$ of fresh COMBO medium. Both infochemical treatments and controls were incubated in triplicates at $20{ }^{\circ} \mathrm{C}$ and $100 \mathrm{rpm}$, under three different light regimes: continuous dark, a 16h:8h light-dark cycle (identical to the Limnotron experiments), or continuous light. The light level was the same as the surface intensity of the Limnotrons, i.e. $120 \mu \mathrm{mol}$ quanta (PAR) $\mathrm{m}^{-2} \mathrm{~s}^{-1}$. Algae samples were taken twice a day during day $0-2$, daily during day 2-8 and every second day during day 8-18. Samples were analysed on cell densities and volumes using an electronic particle counter (Coulter Multisizer 
II, $100 \mu \mathrm{m}$ orifice), and checked for species composition and infection using a light microscope. As data were non-normal and heteroscedastic, we used the MannWhitney U-test to compare colony sizes within treatments, and the Kruskall-Wallis test to compare relaxation times between treatments.

\subsection{Discussion of costs}

Loss rates due to sedimentation losses are described as (Visser et al. 1996):

$$
k_{\text {sed }}=v_{\text {sed }} \cdot Z_{\text {mix }}{ }^{-1}
$$

where $k_{\text {sed }}=$ loss rate due to sedimentation $\left(\mathrm{d}^{-1}\right), v_{\text {sed }}=$ intrinsic settling velocity $\left(\mathrm{m} \cdot \mathrm{d}^{-1}\right)$ and $Z_{m i x}=$ mixing depth $(\mathrm{m})$. The expected intrinsic settling velocities of particles in a laminar environment (i.e. particles $<500$ $\mu \mathrm{m}$ diameter) is given by Stokes' Law (Hutchinson 1967):

$$
v_{\text {sed }}=\frac{\left(\rho_{p}-\rho\right) \cdot g \cdot D^{2}}{18 \cdot \rho \cdot v \cdot f}
$$

where $v_{\text {sed }}=$ settling velocity $\left(\mathrm{m} \mathrm{s}^{-1}\right), \rho_{p}=$ particle density $\left(\mathrm{g} \mathrm{m}^{-3}\right), \rho=$ density of water $\left(\mathrm{g} \mathrm{m}^{-3}\right), g$ =gravitational acceleration $\left(\mathrm{m} \mathrm{s}^{-2}\right), D=$ diameter of the particle $(\mathrm{m}), v$ $=$ kinematic viscosity $\left(\mathrm{m}^{2} \mathrm{~s}^{-1}\right)$, and $f=$ shape factor (dimensionless). Sedimentation loss rates should thus be proportional to $D^{2}(\mathrm{Eqs} 1,2)$, i.e. proportional to $\mathrm{MPV}^{2 / 3}$.

Grazing loss rates were calculated from daily clearance rates, using fitted type II functional response models from grazing experiments of $B$. calyciflorus feeding on differently sized $S$. obliquus and on Desmodesmus quadricauda (Turpin) Hegewald (Verschoor et al. 2007). We used densities typical for eutrophic systems when Scenedesmus and Brachionus co-dominate the plankton (Jeppesen et al. 1990): $1.5 \mathrm{mg} \mathrm{C}$ (15000 ind.) B. calyciflorus $\mathrm{L}^{-1}$ and $15 \mathrm{mg} \mathrm{C}\left(48 \mathrm{~mm}^{3}\right)$ S. obliquus $\mathrm{L}^{-1}$. To compare grazing losses with sedimentation losses, we calculated sedimentation loss rates (Eqs 1 and 2) for a $1 \mathrm{~m}$ deep water column. These sedimentation loss rates were scaled according to the actual loss rates obtained from the controls in the Limnotron experiment, since we did not know the exact values of some parameters.

\section{RESULTS}

\subsection{Limnotron experiment}

Phytoplankton biomass development in the Limnotrons started with a growth phase without significant differences in growth between the herbivore treatments and controls. Regression coefficients of growth rates during the first 5 days were significant, but these coefficients did not differ significantly between treatments and controls $\left(F_{1,2}=0.93, P=0.4371\right)$. Biovolume-specific growth rates \pm standard error (SE) were $0.458 \pm$ $0.026 \mathrm{~d}^{-1}$ in the controls $\left(F_{1,7}=315.51, P<0.0001, r^{2}=\right.$ $0.978)$ and $0.395 \pm 0.012 \mathrm{~d}^{-1}$ in the herbivore treatments
$\left(F_{1,7}=1115.26, P<0.0001, r^{2}=0.994\right)$. Between day 7 and day 11 the phytoplankton had reached carrying capacity, and after this the phytoplankton concentration started to decline exponentially (Fig. 1A). The zooplankton itself had a short growing period, followed by a rapid decline from day 5 onwards to extinction (Fig. 1A).
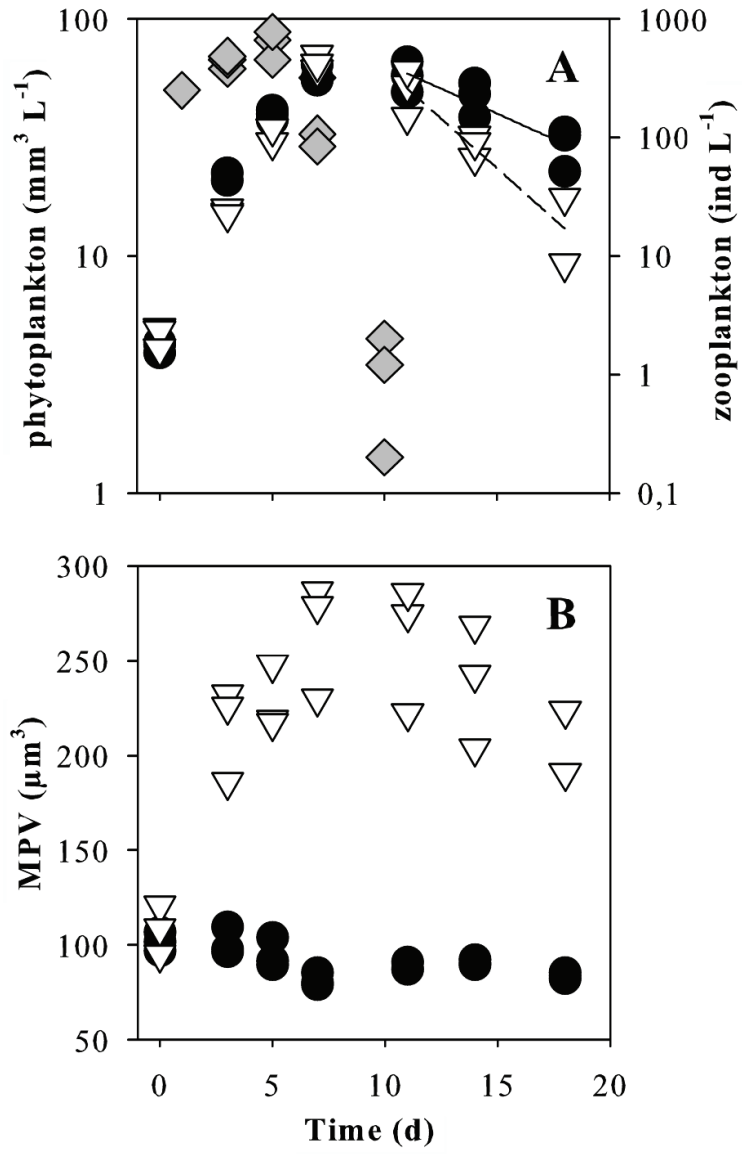

Fig. 1. Dynamics of algal biomass and zooplankton densities during the Limnotron experiment. A, algal biovolume in both control (filled circles) and herbivore (open triangles) treatments, and abundance of Brachionus calyciflorus in the herbivore treatments (grey diamonds). Note the logarithmic scales. Regressions of algal biomass during relaxation periods are given for controls (solid lines) and herbivore treatments (dashed lines). B, mean particle volumes (MPV) of Scenedesmus obliquus cells and colonies, symbols for controls and herbivore treatments as in $1 \mathrm{~A}$.

The algal mean particle volume in the herbivore treatment was significantly greater than the controls from the first sample after grazer addition (day 3 ) until the end of the experiment (Fig. 1B, all $P<0.05$ ), except for day $18(P=0.833)$, due to a missing sample in the herbivore treatments (Fig. 1B). Scenedesmus reached its maximum colony size several days after the maximum herbivore density (Fig. 1). Following the decline of the herbivores, mean particle volume decreased again in the herbivore treatments (Fig. 1B), and mean colony size 

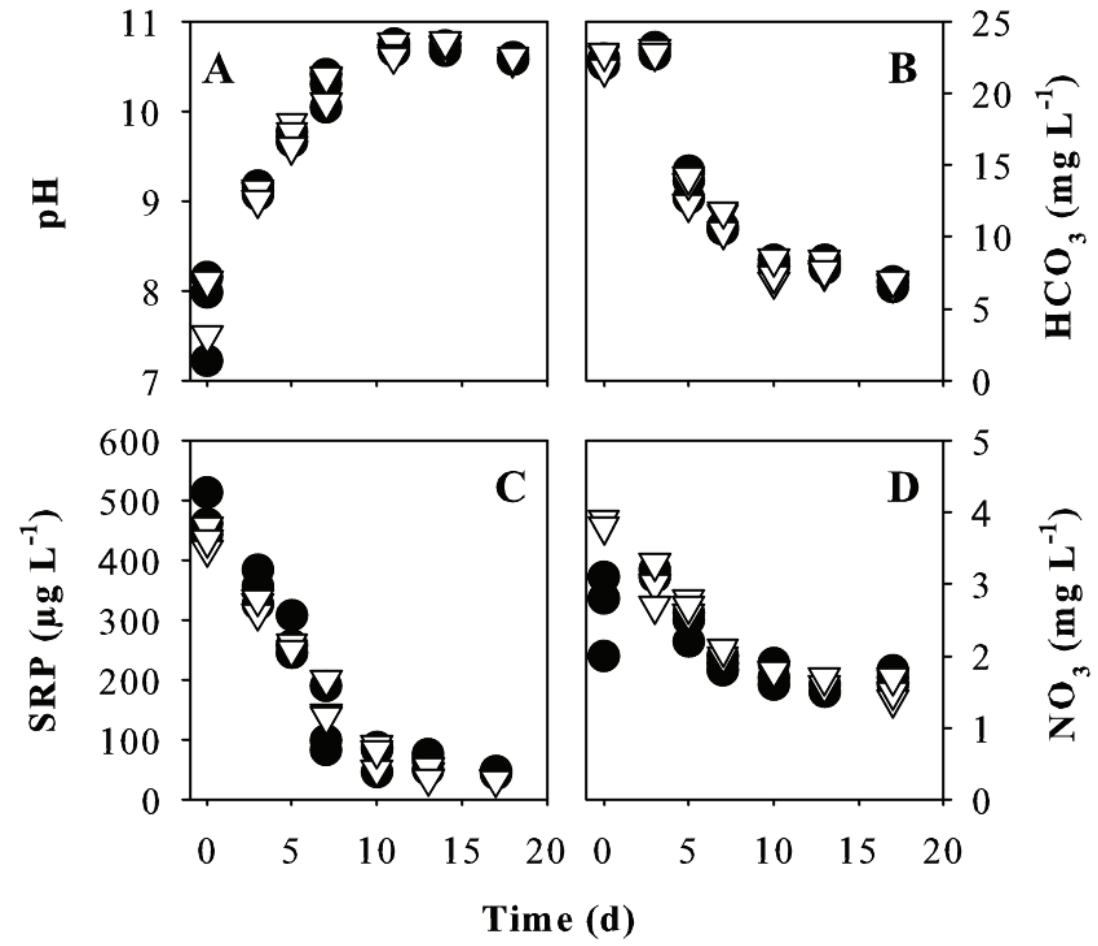

Fig. 2. Dynamics of $\mathrm{pH}$ and dissolved nutrients during the Limnotron experiment, in both control (filled circles) and herbivore treatments (open triangles). A, $\mathrm{pH} ; \mathbf{B}$, Bicarbonate concentration $\left(\mathrm{HCO}_{3}\right)$; C, Soluble reactive phosphorus (SRP) concentration; D, Nitrate $\left(\mathrm{NO}_{3}\right)$ concentration.

went down from approximately 4 cells per colony (day 3) to 2-3 at the end of the experiment, indicating that the typically 4-celled colonies started to disintegrate. Lntransformed seston volume data during decline phase had significant regressions for both control $\left(F_{1,7}=\right.$ 24.33, $P=0.0017, r^{2}=0.777$, continuous line in Fig. $1 \mathrm{~A})$ and herbivore treatment $\left(F_{1,6}=39.39, P=0.0007\right.$, $r^{2}=0.868$, dashed line in Fig. 1A), and were significantly different $\left(F_{1,2}=33.76, P=0.0284\right)$. The corresponding loss rates $( \pm \mathrm{SE})$ were $-0.098 \pm 0.020 \mathrm{~d}^{-1}$ for the controls and $-0.194 \pm 0.031 \mathrm{~d}^{-1}$ for the herbivore treatment.

Oxygen was (super)saturated throughout the experiment but not significantly different between both treatments (not shown). By day 10, SRP was almost depleted, whereas $\mathrm{HCO}_{3}$ and $\mathrm{NO}_{3}$ were still present (Fig. 2B-C). No significant differences were found in $\mathrm{pH}$ and the dissolved inorganic nutrients $\mathrm{HCO}_{3}, \mathrm{SRP}$, and $\mathrm{NO}_{3}$ between treatments (Fig. 2B-C).

Microscopic investigation and 18S rRNA DGGEs showed that the species composition remained unialgal throughout the experiment. Also we did not observe hyphae, sporangia or zoospores, nor lysis of phytoplankton cells. The 16S rRNA DGGE analyses suggests that the bacterial community gradually became dominated by a single species, both in controls and herbivory treatments (DGGEs not shown). Therefore, differences in algal growth, sedimentation, or size could only be attributed to treatment (herbivore) effects.

\subsection{Bioassay experiment}

The decrease in MPVs depended strongly on the light regime: without light MPVs decreased immediately; in the light-dark cycle MPVs first decreased (the experiment started with a dark cycle), then increased and then decreased again; and in the full light MPVs first increased and then gradually decreased. In the full light treatment, induced colonies were significantly greater from day 0 through day 10, in the light-dark treatment from day 0 through day 12 , and in the full dark treatment from day 0 through day 8 , and on day 12 (all $P=0.0495$ ) (Fig. 3).

Since mean particle volumes also decreased in the controls (Fig. 3), clearer patterns emerged when we compared the disintegration times, i.e. the time when MPV first went below the average pre-induction MPVs of $98 \mu^{3}$ (solid horizontal lines in figure 3). We found a significant treatment effect for the disintegration times $(P=0.0226, H=7.58, d f=2)$, and their ranges were 8 $12 \mathrm{~d}$ for full light, 4 days for the light:dark treatment and $1-1.5 \mathrm{~d}$ for the full dark treatment.

\section{DISCUSSION AND CONCLUSIONS}

One of the main results of our Limnotron experiment is that we showed that colony formation still occurs in systems with sedimentation and temporal and spatial heterogeneity in light intensity. Hence, it is likely 


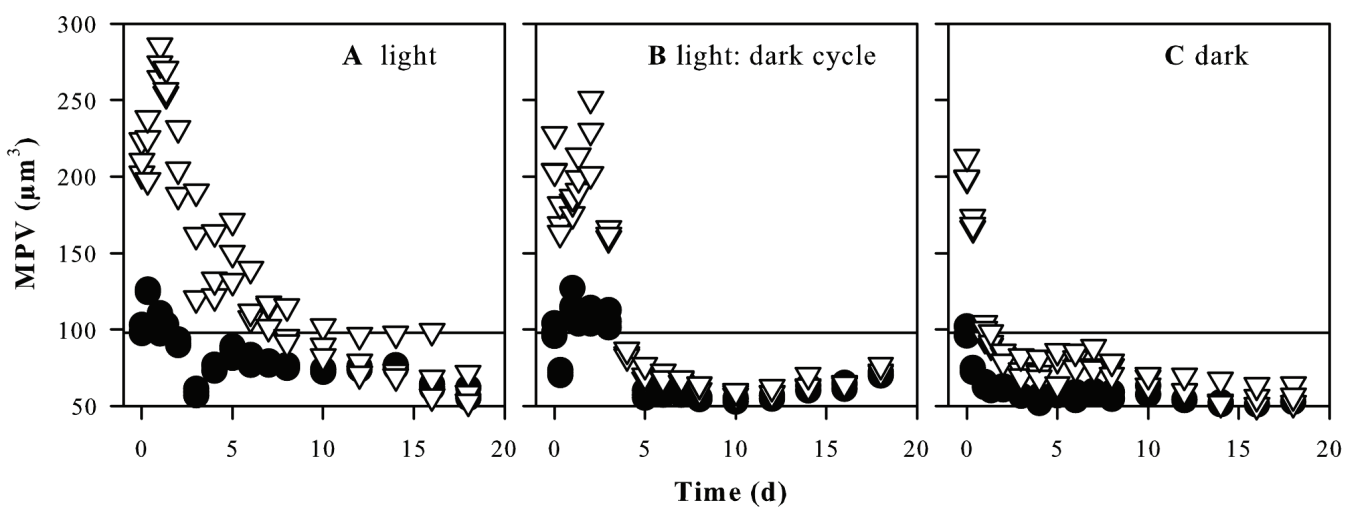

Fig. 3. Colony sizes of Scenedesmus obliquus during the relaxation time bioassays, expressed as mean particle volumes (MPV). Algae have been exposed either to control test water (filled circles) or to herbivore test water (open triangles). A, continuous light; B, a light-dark regime of 16:8 h; C, continuous dark.

that this type of induced defences against herbivore plays a role in natural systems. Immediately after herbivores were introduced in the Limnotrons, Scenedesmus started to form colonies, although it took some time before colonies were fully developed. One unexpected aspect of our experiment was that the herbivores declined rapidly after the first 5 days. This was probably due to the high $\mathrm{pH}$, which exceeded the upper limit for B. calyciflorus ( $\mathrm{pH}$ 10.5: Mitchell 1992), and which also has been observed as critical for herbivorous zooplankton persistence in natural hypertrophic systems with Scenedesmus (e.g., Jeppesen et al. 1990). Even so, this unplanned disappearance of the herbivore yielded a unique opportunity to: 1) compare the sedimentation rates of the algae in the Limnotrons, since herbivory was absent now, making sedimentation the only loss process remaining; and 2) observe the rate of colony disintegration in the Limnotrons, and compare this with the same rates under more controlled conditions in the bioassays. Combining the findings on sedimentation rates in the Limnotrons and colony disintegration in both Limnotrons and bioassays, we were able to estimate the costs of defences during a less studied period of the defence cycle, i.e. during the relaxation phase. As far as we know, this is the first time that this aspect has been studied for microalgae.

\subsection{Sedimentation rates}

In the Limnotrons we found significantly different loss rates between controls and herbivore treatments during the relaxation phase. Since herbivory, parasites and lysis were absent during that phase, we conclude that these differences are solely due to differences in sedimentation rates. Based on volume-specific loss rates, estimated settling velocities are $0.132 \mathrm{~m} \mathrm{~d}^{-1}$ for the controls and $0.262 \mathrm{~m} \mathrm{~d}^{-1}$ for the herbivory treatments. (Eq. 1; system depth $=$ mixing depth $=1.35 \mathrm{~m}$ ). These observed differences $(1.98 \times$ enhancement of sedimentation rates) compare very well with the theoretically expected settling velocities (Eq. 2, $v_{\text {sed }} \sim \mathrm{MPV}^{2 / 3}$ ), which should be $1.95 \times$ as high for the herbivory treatment as for the controls. Calculations are based on the average MPV of $239 \mu \mathrm{m}^{3}$ for the algae during relaxation phase and an average MPV of $88 \mu \mathrm{m}^{3}$ for the algae in the controls (Fig. 1).

Our estimated sedimentation rates are comparable to measurements of Lürling \& Van Donk (2000) on the same strain of $S$. obliquus, where undefended algae (MPV $107 \mu \mathrm{m}^{3}$ ) settled at $0.069 \pm 0.059 \mathrm{~m} \mathrm{~d}^{-1}$, and defended (MPV $477 \mu \mathrm{m}^{3}$ ) at $0.304 \pm 0.096 \mathrm{~m} \mathrm{~d}^{-1}$. Moreover, our settling velocities are in the range found for other Scenedesmaceae: $0.10 \pm 0.06 \mathrm{~m} \mathrm{~d}^{-1}$ for $S$. $a c u$ tiformis in the Canadian lake St. George (Burns \& Rosa 1980), $0.02-0.25 \mathrm{~m} \mathrm{~d}^{-1}$ for Scenedesmus-dominated phytoplankton in the Danish lake Søbygård (Jeppesen et al. 1990), and $0.27 \pm 0.04 \mathrm{~m} \mathrm{~d}^{-1}$ for exponentially growing D. quadricauda in laboratory cultures (Titman $\&$ Kilham 1976). Sometimes, even much higher settling velocities have been observed for Scenedesmaceae, e.g. $0.89 \pm 0.06 \mathrm{~m} \mathrm{~d}^{-1}$ for stationary growing $D$. quadricauda in the laboratory (Titman \& Kilham 1976), and $1.1-1.2$ $\mathrm{m} \mathrm{d}^{-1}$ in the Dutch lake Nieuwe Meer (Visser et al. 1996). Although turbulence in the field may be higher, this does not imply that sedimentation rates in the field are lower; rather the contrary may be true (Ruiz et al. 2004). In our experiment, loss rates in the herbivory treatment following the grazer die-off were already $1.98 \times$ higher as in the controls, showing that sedimentation may impose a significant cost to colony-forming algae.

\subsection{Colony disintegration: light dependence and chemical footprints}

The results of the bioassay experiment showed the importance of the light period for the maintenance of colonies. In continuous light, colonies disintegrated much slower ( 8 - 12 days) as compared to colonies in a light:dark cycle (4 days), whereas colonies disintegrated almost immediately ( $1-1.5$ days) in the absence of light. Decrease of $S$. obliquus colony size in the dark 


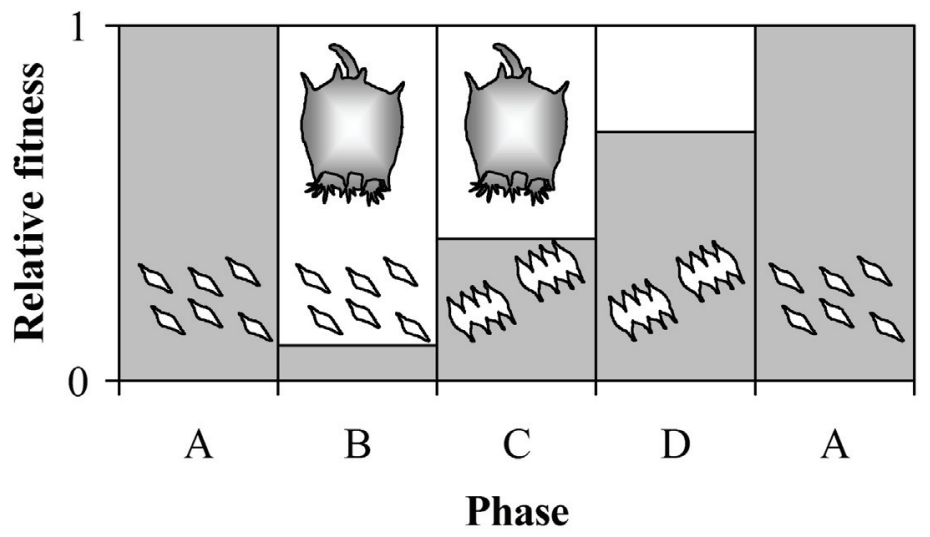

Fig. 4. Different phases during the inducible defence cycle of Scenedesmus obliquus. Relative fitness (grey area) is scaled to a maximum of 1, representing fitness of undefended algae in the absence of herbivory, so that the white area can be interpreted as fitness costs (i.e., costs of defence plus mortality due to grazing). A, undefended phase, herbivory is absent and algae are undefended; B, induction phase, herbivory is present (denoted by picture of Brachionus) but algae have not yet fully developed their defences so that losses due to herbivory (white area) are high; $\mathbf{C}$, defence phase, herbivory is present and algae are fully defended, which lowers losses due to herbivory (white area); D, relaxation phase, defences are still present but herbivory is absent or very low. Note that being fully defended does not mean that algal edibility or grazing mortality become zero.

and at low light intensities has also been found by Senger \& Fleischhacker (1978) and M. Lürling (personal communication). Disintegration of colonies in the dark has also been observed for other Chlorophytes, such as S. acuminatus (Dehning \& Tilzer 1989) and Chlorella vulgaris (Boraas et al. 1998). Microscopic investigation of the Scenedesmus in our bioassays revealed that cells remained intact during colony disintegration but adhered progressively less within the colony matrix, which is indicative of degenerative stress (Trainor 1998) and quite different from normal cell division. Periods of active photosynthesis seem to be a prerequisite for colonies to retain their morphology.

In the Limnotron experiments, with a $16: 8 \mathrm{~h}$ lightdark cycle, disintegration of the similarly sized colonies took 10 to 15 days, which is longer than the disintegration times found in the bioassays, even though the Limnotron algae were subject to sedimentation and probably received lower average light levels. Therefore, this difference can most likely be explained by slowly-degrading herbivore-excreted infochemicals still present after extinction of the rotifers in the Limnotron experiment. This 'ghost of herbivory past' caused a delay in relaxation time, with additional ecological costs, which may be very relevant in natural systems with dynamic variation in the strength of herbivory.

\subsection{Integrating fitness costs in the defence cycle}

We observed that Scenedesmus colonies were tracking herbivore presence, albeit with some delays, since herbivory and defence expression do not perfectly match. Hence, the relative algal fitness varies in time, which we depicted graphically in figure 4 . During the undefended phase, when herbivory is low or absent, both herbivory losses and costs of defences are low and relative fitness is maximal (Fig. 4A). When herbivory increases, the induction phase starts (Fig 4B); relative fitness drops dramatically because of high losses to herbivory, whereas defences have not yet been fully developed (Fig. 4B). During the defence phase, defences have developed fully, so losses to herbivory decrease as compared to the induction phase (Fig. 4C). Since herbivory reduces the relative fitness of the algae to a larger extent than the defence costs, relative fitness during the defence phase is higher than during the induction phase. During the relaxation phase, herbivory diminishes, but defences and associated costs remain present for some while (Fig. 4D) until full relaxation has been reached again. The temporal mismatch between maximum herbivory and maximum colony size is an unavoidable consequence of the fact that the processes of infochemical dispersal and degradation on one hand, and colony formation and disintegration on the other hand, all require a certain minimal time span.

We observed delays in response to both presence and absence of the herbivore-released infochemicals, and, what is more, the duration of relaxation phase was much longer than that of the induction phase. Although relaxation times should be as short as possible to minimise costs, literature on the relative timing of inducible defences suggests that quick induction and slow relaxation prevail in many organisms (e.g., Schultz 1988; Karban \& Baldwin 1997; Huntzinger et al. 2004). The time delays involved in induction and relaxation of defences may cause cyclic dynamics (e.g., Haukioja 1980; Schultz 1988; Underwood 1999) or may stabilize dynamics when delays are absent or minimal (Abrams \& Walters 1996; Vos et al. 2004a; Dahlgren et al. 2007). Therefore, these time lags are important in the evolution of inducible defences (De Witt et al. 1998; Shudo \& Iwasa 2001; Gabriel et al. 2005).

Slow relaxation may occur because many types of morphological defences are not quickly reversible and do not require high maintenance costs, such as different 
shell shapes in intertidal barnacles (Lively et al. 2000) or spines on Acacia trees (Young \& Okello 1998). However, this purely physiological perspective is not satisfactory when organisms are facing high ecological costs of defences. Slow relaxation could only evolve when the sum of all fitness costs involved is still lower compared to either being constitutively defended or being undefended. Because present herbivory is usually a good predictor of future herbivory, slow relaxation may be an adaptive strategy in an unpredictable environment (Young \& Okello 1998). In natural systems, this may lead to a dynamic equilibrium between sedimentation, colony disintegration and herbivory: (a) algae are exposed to herbivory and form colonies; (b) colonies settle out of the upper part of the water column; (c) at a certain depth, colonies disintegrate because the photosynthetic requirements for colony maintenance are not met anymore; (d) when still in the mixing zone, unicells may become resuspended and serve as inoculum for subsequent growth (Trainor 1998; Lürling 2003b), and may again be subject to herbivory and sedimentation. Although this may suggest that sedimentation due to slow relaxation offers an attractive temporary refugium from predation, this option always involves loss of algae out of the mixing zone and is therefore only attractive when frequent resuspension occurs (StåhlDelbanco \& Hansson 2002) and/or for motile algae (Hansson 1996; Rengefors et al. 1998) and when losses to sedimentation are lower than the expected losses to predation.

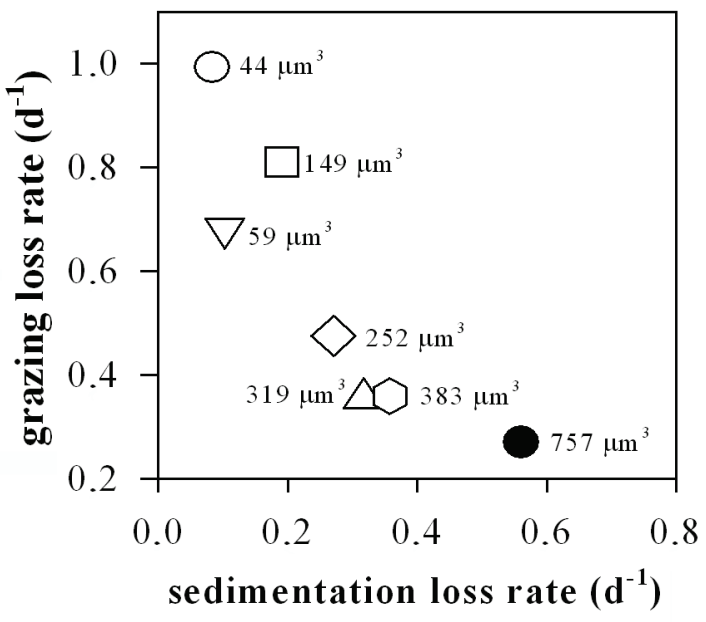

Fig. 5. Estimated grazing versus sedimentation costs from published data for differentially sized Scenedesmaceae, expressed as daily biomass loss rates for a herbivore density of 15 Brachionus calyciflorus $\mathrm{mL}^{-1}$. With increasing size (from top left to bottom right) grazing losses decrease, at the cost of increasing sedimentation. Shown are results for Scenedesmus obliquus from different publications, having mean particle volumes between $44 \mu \mathrm{m}^{3}$ and $383 \mu \mathrm{m}^{3}$ (open symbols), and for Desmodesmus quadricauda $\left(757 \mu \mathrm{m}^{3}\right.$, filled circle).
To get more insight into the trade-off between sedimentation and grazing losses over a range of possible particle sizes, we compared estimates of removal rates by Brachionus and sedimentation rates for morphologically similar Scenedesmaceae in the particle size range 44-757 $\mu \mathrm{m}^{3}$ (Fig. 5). These rates have been calculated on the basis of estimated functional response parameters from grazing data (Verschoor et al. 2007). The largest species, D. quadricauda (filled circle in Fig. 5), has a fixed (non-inducible) morphology and can be regarded as a constitutively defended species (Verschoor et al. 2007). With increasing size of the algae, grazing losses to Brachionus decrease whereas sedimentation losses increase simultaneously (Fig. 5). This clearly shows the trade-off between these two types of costs and helps us in understanding the occurrence of slow defence relaxation in natural ecosystems.

\section{ACKNOWLEDGEMENTS}

This is publication 4544 of the Netherlands Institute of Ecology (NIOO-KNAW).We thank Klaas Siewertsen for nutrient analyses, Guus Postema, Hennie Uittenhout and Piet Schouten for technical assistance, Boris Massieux for 16S and 18S DGGE analysis, Marten Scheffer for a stimulating discussion on costs of slowness, Gregor Fussmann for the suggestion to show the graphical relationship between grazing and sedimentation losses (trade-off curve), Wolf Mooij and Matthijs Vos for valuable comments on earlier versions of the manuscript, and Bill DeMott for valuable comments on the submitted manuscript and linguistic help.

\section{REFERENCES}

Abrams, P.A. \& C.J. Walters. 1996. Invulnerable prey and the paradox of enrichment. Ecology, 77: 1125-1133.

Boraas, M.E., D.B. Seale \& J.E. Boxhorn. 1998. Phagotrophy by a flagellate selects for colonial prey: a possible origin of multicellularity. Evol. Ecol., 12: 153-164.

Burns, N.M. \& F. Rosa. 1980. In situ measurement of the settling velocity of organic carbon particles and 10 species of phytoplankton. Limnol. Oceanogr., 25: 855-864.

Dahlgren, J., L. Oksanen, M. Sjödin \& J. Olofsson. 2007. Interactions between gray-sided voles (Clethrionomys rufucanus) and bilberry (Vaccinium myrtillus), their main winter food plant. Oecologia, 152: 525-532.

Dehning, I. \& M. Tilzer, 1989. Survival of Scenedesmus acuminatus (Chlorophyceae) in darkness. J. Phycol., 25: 509-515.

DeWitt, T.J., A. Sih, \& D.S. Wilson. 1998. The costs and limits of phenotypic plasticity. Trends Ecol. Evol., 13: 77-81.

Gabriel, W., B. Luttbeg, A. Sih \& R. Tollrian. 2005. Environmental tolerance, heterogeneity, and the evolution of reversible plastic responses. Am. Nat., 166: 339-353.

Hansson, L.-A. 1996. Behavioural response in plants: adjustment in algal recruitment induced by herbivores Proc. $R$. Soc. Lond. B Biol. Sci., 263: 1241-1244.

Hessen, D.O. \& E. van Donk. 1993. Morphological changes in Scenedesmus induced by substances released from Daphnia. Arch. Hydrobiol., 127: 129-140.

Huisman, J., M. Arrayás, U. Ebert \& B. Sommeijer. 2002. How do sinking phytoplankton species manage to persist? Am. Nat., 159: 245-254. 
Huntzinger, M., R. Karban, T.P. Young \& T.M. Palmer. 1994. Relaxation of induced indirect defenses of acacias following exclusion of mammalian herbivores. Ecology, 85: 609-614.

Hutchinson, G.E. 1967. A Treatise on Limnology. 2. J. Wiley $\&$ Sons, New York: 1115 pp.

Jeppesen, E., M. Søndergaard, O. Sortkjær, E. Mortensen \& P. Kristensen. 1990. Interactions between phytoplankton, zooplankton and fish in a shallow, hypertrophic lake: a study of phytoplankton collapses in lake Søbygård, Denmark. Hydrobiologia, 191:149-164.

Karban, R. \& I.T. Baldwin. 1997. Induced Responses to Herbivory. Univ. Chicago Press, Chicago: $300 \mathrm{pp}$.

Kilham, S.S., D.A. Kreeger, S.G. Lynn, C.E. Goulden \& L. Herrera. 1998. COMBO: a defined freshwater culture medium for algae and zooplankton. Hydrobiologia, 377: 147159.

Lampert, W., K.-O. Rothhaupt \& E. Von Elert. 1994. Chemical induction of colony formation in a green alga (Scenedesmus acutus) by grazers (Daphnia). Limnol. Oceanogr., 39: 1543-1550.

Lively, C.M., W.N. Hazel, M.J. Schellenberger \& K.S. Michelson. 2000. Predator-induced defense: variation for inducibility in an intertidal barnacle. Ecology, 81: 12401247.

Lürling, M. 2003a. The effect of substances from different zooplankton species and fish on the induction of defensive morphology in the green alga Scenedesmus obliquus. $J$. Plankton Res., 25: 979-989.

Lürling, M. 2003b. Phenotypic plasticity in the green algae Desmodesmus and Scenedesmus with special reference to the induction of defensive morphology. Ann. Limnol. - Int. J. Limnol., 39: 85-101.

Lürling, M. \& E. Van Donk. 1997. Morphological changes in Scenedesmus induced by infochemicals released in situ from zooplankton grazers. Limnol. Oceanogr., 42: 783-788.

Lürling, M. \& E. Van Donk. 2000. Grazer-induced colony formation in Scenedesmus: are there costs to being colonial? Oikos, 88: 111-118.

Mitchell, S.A. 1992. The effect of $\mathrm{pH}$ on Brachionus calyciflorus Pallas (Rotifera). Hydrobiologia, 245: 87-93.

Pourriot, R. 1965. Recherches sur l'écologie des rotifères. Vie et Milieu, suppl 21: 224 pp.

Rengefors, K., I. Karlsson \& L.-A. Hansson, 1998. Algal cyst dormancy: a temporal escape from herbivory. Proc. $R$. Soc. Lond. B Biol. Sci., 265: 1353-1358.

Ruiz, J., D. Macias \& F. Peters. 2004. Turbulence increases the average settling velocity of phytoplankton cells. Proc. Natl. Acad. Sci. USA, 101: 17720-17724.

Schultz, J.C. 1988. Plant responses induced by herbivory. Trends Ecol. Evol., 3: 45-49.

Senger, H. \& P. Fleischhacker. 1978. Adaptation of the photosynthetic apparatus of Scenedesmus obliquus to strong and weak light conditions. I. Differences in pigments, photosynthetic capacity, quantum yield and dark reactions. Physiol. Plant., 43: 35-42.

Shudo, E. \& Y. Iwasa. 2001. Inducible defense against pathogens and parasites: optimal choice among multiple options. J. Theor. Biol., 209: 233-247.

Siver, P.A. \& F.R. Trainor. 1981. Morphological control and physiology of Scenedesmus strain 170. Phycologia, 20: 1-11.

Sokal, R.R. \& F.J. Rohlf. 2000. Biometry. The Principle and Practice of Statistics in Biological Research. 3rd ed. W.H. Freeman \& Co., New York, 887 + xix pp.
Ståhl-Delbanco, A. \& L.-A. Hansson, 2002. Effects of bioturbation on recruitment of algal cells from the "seed bank" of lake sediments. Limnol. Oceanogr., 47: 1836-1843.

Titman, D. \& P. Kilham. 1976. Sinking in freshwater phytoplankton: some ecological implications of cell nutrient status and physical mixing processes. Limnol. Oceanogr., 21: 409-417.

Tollrian, R. \& C.D. Harvell. 1999. The Ecology and Evolution of Inducible Defenses. Princeton Univ. Press, Princeton, $383+$ vi pp.

Trainor, F.R. 1998. Biological aspects of Scenedesmus (Chlorophyceae) - phenotypic plasticity. Nova Hedwigia Beih., 117: 367 pp.

Underwood, N. 1998 The timing of induced resistance and induced susceptibility in the soybean-Mexican bean beetle system. Oecologia, 114: 376-381.

Valladares, F., E. Gianoli \& J.M. Gómez. 2007. Ecological limits to plant phenotypic plasticity. New Phytol., 176: 749-763.

Van Donk, E., M. Lürling \& W. Lampert. 1999. Consumerinduced changes in phytoplankton: inducibility, costs, benefits, and the impact on grazers. In: R. Tollrian \& C.D. Harvell (Eds), The Ecology and Evolution of Inducible Defenses. Princeton Univ. Press, Princeton: 89-103.

Van der Stap, I., A.M. Verschoor, N.R. Helmsing \& W.M. Mooij. 2007. Induced defenses in herbivores and plants differentially modulate a trophic cascade. Ecology, 88: 2474-2481.

Verschoor, A.M., J.J. Takken, B. Massieux \& J. Vijverberg. 2003. The Limnotrons: a facility for experimental community and food web research. Hydrobiologia, 491: 357-377.

Verschoor, A.M., I. van der Stap, N.R. Helmsing, M. Lürling \& E. van Donk. 2004a. Inducible colony formation within the Scenedesmaceae: Adaptive responses to infochemicals from two different herbivore taxa. J. Phycol., 40: 808-814.

Verschoor, A.M., M. Vos \& I. van der Stap. 2004b. Inducible defences prevent strong population fluctuations in bi- and tritrophic food chains. Ecol. Lett., 7: 1143-1148.

Verschoor, A.M., Y. Zadereev \& W.M. Mooij. 2007. Infochemical-mediated trophic interactions between the rotifer Brachionus calyciflorus and its food algae. Limnol. Oceanogr., 52: 2109-2119.

Visser, P.M., L. Massault, J. Huisman \& L.R. Mur. 1996. Sedimentation losses of Scenedesmus in relation to mixing depth. Arch. Hydrobiol., 136: 289-308.

Von Elert, E. \& A. Franck. 1999. Colony formation in Scenedesmus: grazer-mediated release and chemical features of the infochemical. J. Plankton Res., 21: 789-804.

Vos, M., B.W. Kooi, D.L. DeAngelis \& W.M. Mooij. 2004a. Inducible defences and the paradox of enrichment. Oikos, 105: 471-480.

Vos, M., A.M. Verschoor, B.W. Kooi, F.L. Wäckers, D.L. DeAngelis \& W.M. Mooij. 2004b. Inducible defenses and trophic structure. Ecology, 85: 2783-2794.

Wiltshire, K.H. \& W. Lampert. 1999. Urea excretion by Daphnia: A colony-inducing factor in Scenedesmus? Limnol. Oceanogr., 44: 1894-1903.

Yasumoto K., A. Nishigami, H. Aoi, C. Tsuchihashi, F. Kasai, T. Kusumi \& T. Ooi. 2008. Isolation and absolute configuration determination of aliphatic sulfates as the Daphnia kairomones inducing morphological defense of a phytoplankton - Part 2. Chem. Pharm. Bull., 56: 129-132.

Young, T.P. \& B.D. Okello. 1998. Relaxation of an induced defense after exclusion of herbivores: spines on Acacia drepanolobium. Oecologia, 115: 508-513. 